\title{
Third-party logistics in construction: the case of a large hospital project
}

\author{
Andreas Ekeskär and Martin Rudberg
}

\author{
Linköping University Post Print
}

\section{Tweet}

N.B.: When citing this work, cite the original article.

This is an electronic version of an article published in:

Andreas Ekeskär and Martin Rudberg, Third-party logistics in construction: the case of a large hospital project, 2016, Construction Management and Economics, (34), 3, 174-191.

Construction Management and Economics is available online at informaworldTM:

http://dx.doi.org/10.1080/01446193.2016.1186809

Copyright: Taylor \& Francis (Routledge): STM, Behavioural Science and Public Health Titles http://www.routledge.com/

Postprint available at: Linköping University Electronic Press

http://urn.kb.se/resolve?urn=urn:nbn:se:liu:diva-128817 


\title{
Third-party Logistics in Construction: The Case of a Large Hospital Project
}

\author{
Andreas Ekeskär (andreas.ekeskar@liu.se) \\ Department of Science and Technology, Linköping University, Sweden \\ Martin Rudberg (martin.rudberg@liu.se) \\ Department of Science and Technology, Linköping University, Sweden
}

\begin{abstract}
The construction supply chain is of temporary nature and complex, with many interactions between multiple actors in different construction projects. This challenging context typically leads to relatively higher costs and lower productivity, compared to other industries. Supply chain management (SCM) has been put forward as a mean to better handle this challenging context. As a part of SCM initiatives some construction industry stakeholders have turned to third-party logistics (TPL) providers, especially in large construction projects. The use of TPL providers is a new, and under-investigated, phenomenon in the construction industry. The main purpose of this study is thus to explore the use of a TPL provider in a large construction project and to analyse its resulting effects. Driving forces and possible concerns for implementing TPL are identified and the possibility for TPL to be a facilitator for implementing SCM in construction is investigated. The research is based on a literature review and an explorative case study of a large hospital project in Sweden, where the client and the main contractor have initiated the use of a TPL provider to coordinate sourcing and materials handling activities on site. The results show positive effects on establishing an effective interface between the construction site and the supply chain. The results also show that a TPL solution facilitates an increase in productive work at the construction site itself, a reduction of costs and an increased utilization of site assets. On the downside, the study also shows a lack of SCM knowledge amongst the involved actors in the project, hindering them to reap the full potential of TPL.
\end{abstract}


Keywords: Case study, Construction logistics, Construction supply chain, Supply chain management, Third-party logistics. 


\section{Introduction}

In construction, the products are typically physically big and not mobile, and consequently have to be produced on the site of use. The construction process is projectbased and carried out in temporary organizations (Bakker, 2010), also requiring the establishment of temporary supply chains (Vrijhoef and Koskela, 2000). As much as 60$80 \%$ of the gross work done in construction projects involves the buying-in of materials and services from suppliers and subcontractors (Scholman, 1997), leading to that these supply chain actors heavily impact the performance of construction projects (Dubois and Gadde, 2002; Miller et al., 2002). The construction supply chain can thereby be regarded as complex (Fellows and Liu, 2012) with many interactions between multiple actors during the construction process (Winch, 2001). The inability to manage this complexity is also one of the main reasons for why the construction industry, in general, is suffering from both low productivity and rising production costs (Vrijhoef and Koskela, 2000).

In this complex environment it is believed that creating the right prerequisites for better supply chain management (SCM) will enhance productivity and reduce the total cost (Department for Business Innovation and Skills, 2013; Vrijhoef and Koskela, 2000). Being reliant on other actors in the supply chain, the main contractors play a crucial role in implementing SCM, but it has also been argued that for SCM to be realized in construction there is a need for change driven by the construction clients (Briscoe et al., 2004). As a part of many SCM initiatives, some contractors and clients have started to turn to third-party logistics (TPL) providers, especially in the case of large construction projects. This is a new phenomenon in construction (Langley, 2015) for both the clients and the contractors, but also for the TPL providers, not traditionally being very active in the construction industry. Also suppliers, retailers, building merchants and transport providers face new interfaces and project settings when a TPL provider enters the scene. 
Hence, there is a need to explore how this new phenomenon impacts construction projects in general and the performance of the construction supply chain in particular.

The general aim of this research is therefore to explore the use of TPL in construction. More specifically, the purpose is to investigate the use of a TPL provider in a large construction project, and to analyse the resulting effects on performance for the project and for the construction supply chain. The study is of an explorative nature and the following questions guide the research (also confer Figure 1):

- Research question 1 (RQ1): What are the main driving forces and concerns for implementing TPL in construction?

- Research question 2 (RQ2): What realized and potential effects (positive and negative) can be expected from using TPL in construction projects?

- Research question 3 (RQ3): Can TPL be used as a mean to realize SCM in construction?

The first research question relates to the ongoing debate on pro's and con's with SCM and logistics initiatives in construction (cf. Fearne and Fowler, 2006; Fernie and Tennant, 2013; Meng, 2013; Vrijhoef and Koskela, 2000), and it will be analysed based on a literature review. The main focus of the review is on TPL, in particular on driving forces and concerns for implementing TPL. However, TPL is not an isolated activity, rather it is a part of a supply chain and both affects and is affected by the supply chain actors and the context were TPL is used. Hence, the review also includes a general account on the status of the construction industry and construction supply chains. Research question 2 is investigated through a single case study at a large hospital project in Sweden, where the client through the main contractor has initiated the use of a TPL provider to coordinate sourcing and materials handling cativities on site. Even though the answer to RQ2, strictly 
speaking, is only valid within the frames of the single case setting, the answers from the literature review in RQ1 is used for theoretical generalization (Yin, 2014). Yet, the results must naturally be treated with sound scientific caution. The third research question is grounded in RQ1 and RQ2 and will, within the limits of generalizability from a single case study, address whether TPL increases the logistics awareness and as such can facilitate the implementation of SCM in construction. The conceptual analysis and reasoning that is used to answer RQ3 also identifies areas for further research on the use of TPL in construction.

After this introduction, the research design is presented followed by the literature review and the case study. Then the case results are analysed and contrasted with the findings from the literature review, and the possibility to use TPL as means to realize SCM in construction is discussed. Finally, the conclusions are summarised, contributions are highlighted and suggestions for future research are identified.

\section{Research design}

The research design is visualized in Figure 1. Methodologically the research is divided into three phases. The first phase is a literature review that is used to identify reasons (i.e. driving forces) to why construction companies and construction clients are approaching TPL to enhance operations, but also the obstacles (i.e. concerns) that might be faced. The second phase is based on an empirical study using a single case to identify realized and potential effects from a large construction project where a TPL provider is used as a mean to plan, control and execute logistics and materials handling. In the third phase, the results from the two previous phases are analysed based on analytical and conceptual reasoning (Wacker, 1998). 


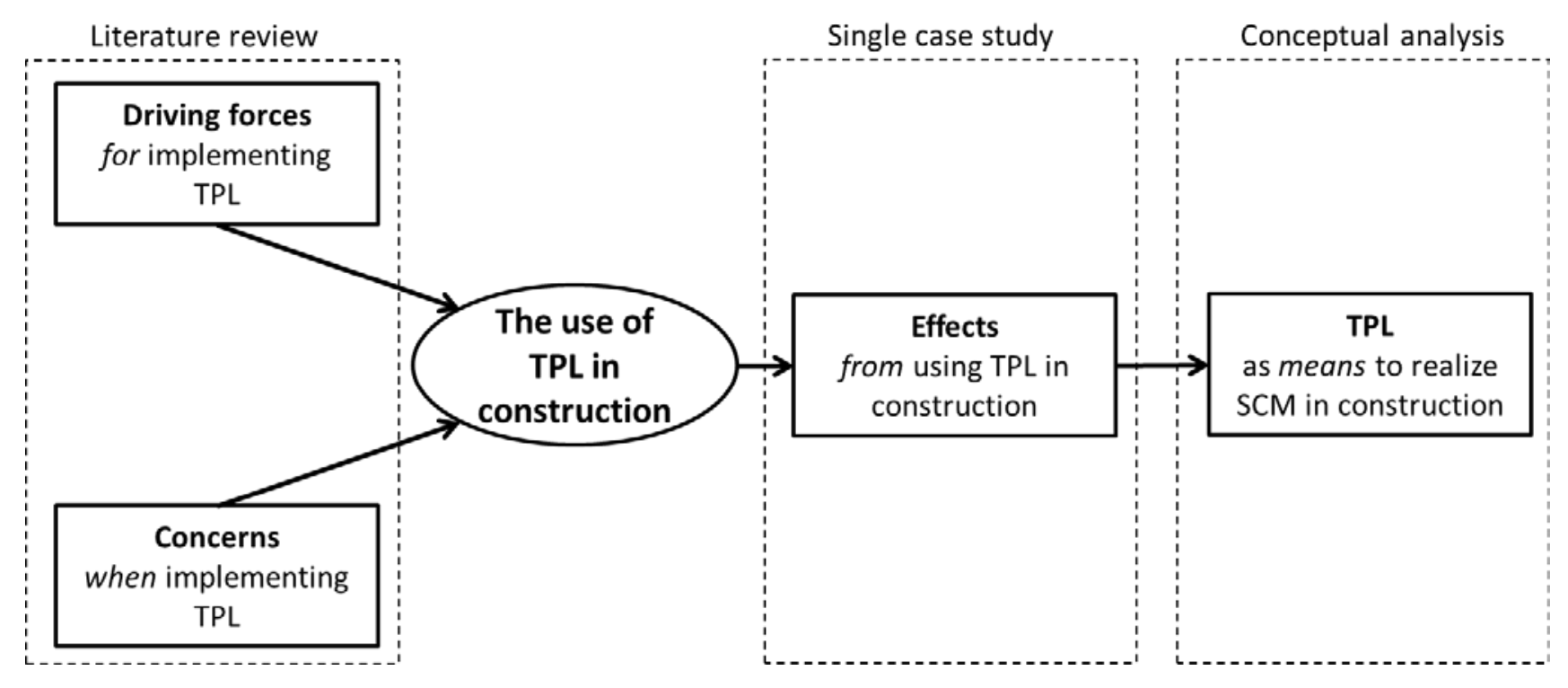

Figure 1 - The research design used in the study.

In terms of literature, the review tries to provide a broad perspective on the construction industry setting and the general performance of the industry. The review also broadly covers the definitions of a supply chain and TPL, as well as how supply chains and TPL should preferably be managed. The main focus is, however, on previous research treating the rationale for implementing TPL, both drivers and barriers, and the experienced effects of TPL. The search was done in databases which contain a large body of literature including peer-reviewed full-text articles, such as ScienceDirect, Scopus, Emerald and EBSCO. To get a broad perspective on TPL, the search focused on wellcited literature reviews and surveys. A such, the review is more of a meta-type review (Jesson et al., 2011), rather than scrutinizing each and every paper on TPL. This was considered suitable, since the goal of the review on TPL was to find the most apparent drivers and barriers as grounds for investigating TPL within a new context and thereby as a new phenomenon. Besides this meta-review on TPL in general, the few accounts in 
literature discussing when TPL has been used in construction are also included in this study.

As for the case study, data has been collected during a period of 1.5 years, thereby including longitudinal aspects. Case studies are regarded a good method for studying new phenomena in exploratory research (Voss, 2009), and the use of a single case study in this early phase of the research is motivated by that the project is revelatory (Yin, 2014) and that it will be possible to study the project over time, as a longitudinal study (Yin, 2014). The case study was divided into three steps: data collection, data analysis, and validation of case study results. The process was, however, not straight forward. Preliminary analyses were carried out while collecting data, and preliminary results were provided to the interviewees and project participants for initial validation. Hence, the process has been iterative, not only concerning the case study itself, but also between the empirical and the literature review phases of the research. For the data collection the main sources have been: on-site visits, participatory observations (e.g. attending meetings), review of project documents (including internal policies, meeting protocols and external project reviews), master's thesis reports and semi-structured interviews. The interviews have been carried out with the project management at the client (2 interviews), managers at the main contractor (1 interview) and sub-contractors (4 interviews), as well as with managers from the TPL provider (3 interviews). The interviews typically lasted between 1 and 1.5 hours, and when necessary clarifications and follow-up questions were asked by e-mail or by phone. Case data was analysed by comparing the main data sources: transcribed interviews, meetings minutes, narratives from the participatory observations, project documents and the two master theses that was carried out during the project. The collected data was used for writing up the case description and for comparing the stakeholders' different perspectives on the experiences and results (i.e. effects) from using a TPL 
provider. The effects were coded in line with the results from the literature review and the case data was reduced in an iterative process narrowing down the vast amount of data into factors resembling driving forces and possible barriers for using TPL in construction. Results and findings from the case study have been validated throughout the project. Interview transcriptions have been sent to the interviewees, preliminary results and conclusions have been discussed during project meetings with the key stakeholders. Final reports have been sent to the project stakeholders and conclusions have been discussed both internally with the project management team and at open seminars with participants from the construction project.

The final phase of the research process is a conceptual analysis of the results from the literature review and the case study. In conceptual research approaches, analytical and empirical methodologies are often combined to provide new insights into a new phenomenon through logical reasoning (Wacker, 1998). The aim of all conceptual research methodologies is to build theory (Meredith, 1993) and exploratory research is a first step towards theory building by providing conceptual description, philosophical conceptualization as well as taxonomies and typologies (Meredith, 1993). Meredith (2001) suggests that a theory-building process starts with a description and explanation of a phenomenon, the building of conceptual constructs and models, and ends with validation and verification of the models. This iterative process continues until the conceptual models get refined and turned into theories. The research presented here, being of an explorative nature, does not claim to provide neither validation of conceptual models nor refined theories. Yet, it aims to describe and explain a new phenomenon and to initiate the building of conceptual constructs and models. 


\section{Literature review}

The construction industry setting

The productivity in the construction industry is considered relatively low (Abdel-Wahab and Vogl, 2011; Fulford and Standing, 2014; Josephson and Chao, 2014), which affects the prices of buildings within the European Union (Eurostat, 2000). To take Sweden as an example, the production costs for buildings have increased more than for other products if indexes are compared (Statistics Sweden, 2015). However, the construction industry also faces unique settings that to some extent can explain the low level of productivity and the high costs. One example being that the construction site can be seen as a temporary factory built around the product (Bygballe and Ingemansson, 2014), products which typically are physically large and immobile and hence have to be built on the site of use. Therefore, construction work is carried out in temporary organizations with temporary supply chains (Behera et al., 2015). Typically, a construction project is dependent on many, often small, firms acting as subcontractors (Dubois and Gadde, 2002; Miller et al., 2002). This fragmentation (Eriksson, 2010) is further enhanced by the different rules and regulations that construction companies typically face (Borgbrant and Apleberger, 2008; Kadefors, 1995).

Examples of the low productivity can for instance be found in the study by Josephson and Saukkoriipi (2005) investigating waste in the construction industry. At a project level, they calculate the waste to be between $30-35 \%$ of the production costs. Looking at the work performed on site, Josephson and Saukkoriipi (2005) measured the amount of direct value adding time a construction worker performs to $17.5 \%$ (indirect value adding time was measured to $25 \%$ ). The waiting time for the construction workers was close to $30 \%$, which is close to two times the direct value adding time. The same goes for machines, none of the studied machines were utilized more than about $50 \%$ of the time. Thunberg 
and Persson (2013) highlight the poor delivery service in the construction industry, indicating that less than $40 \%$ of deliveries are delivered in full (right amount, right time and location, damage free and right documentation). Similarly Vrijhoef and Koskela (2000) exemplify the counterproductive procurement strategies in construction leading to very high handling and logistics costs, sometimes as high as $250 \%$ of the materials procurement price. Frödell (2014) claims that that the procurement strategies are still not in line with the way that operations are performed at site, manifesting the ineffective purchasing procedures in construction. Vrijhoef and Koskela (2000) also describe that many of the problems have their origin upstream in the supply chain, but their effects propagate to the construction site.

The above mentioned and other studies reporting on poor performance data and low productivity in construction indicate that many of the issues, e.g. high costs (Hwang et al., 2009), waste (Josephson and Saukkoriipi, 2005), and waiting time (Thunberg and Persson, 2013), originate from poor logistics performance (Meng, 2012). This is one of the reasons why some authors (e.g. Bankvall et al., 2010; Department for Business Innovation and Skills, 2013; Thunberg and Persson, 2013; Vrijhoef and Koskela, 2000) argue that many of the problems in construction could be mitigated through better managed supply chains and better logistics management.

\section{Supply chain management}

The term supply chain management (SCM) has been around since the early 1980's when it was coined by the consultant Keith Oliver (Harland, 1996). However, the concept can be traced back to Forrester (1958) investigating the interrelationships between separate companies and the management of the related dynamic factors. At the very core of supply chain management is the coordination of the entities in the supply chain and an orientation 
towards closer relationships between the supply chain members (Lambert and Cooper, 2000). In this sense it is important to realize that supply chains exist whether they are managed or not, and a distinction can be made between supply chains as a phenomena that exists in business and the management of those supply chains (Mentzer et al., 2001). It is also important to note that any one organization can be a part of numerous supply chains, and that a supply chain is not a chain of businesses with one-to-one, business-tobusiness relationships, but a network of multiple businesses and relationships that need to be managed (Christopher, 2011; Lambert and Cooper, 2000).

Mentzer et al. (2001) argue that all participating companies must have a so-called supply chain orientation (SCO) for SCM to be realized in full. To be supply chain oriented a company must be willing to, strategically and systematically, address issues such as trust, commitment, interdependency, shared goals and visions, and the acceptance of a leader role in the supply chain. Since a supply chain, by definition, is made up of at least three or more companies (entities), all participating companies must have a SCO to be able to realize SCM across the supply chain (Mentzer et al., 2001). SCO is a prerequisite and individual members of the supply chain must first coordinate activities within the company (Lambert and Cooper, 2000), but disjointed supply chain tactics (such as Lean, JIT, BIM, Bar codes, etc.) is not SCM unless they are coordinated over the supply chain (Mentzer et al., 2001). If the single company antecedents lead to a SCO that is implemented across the supply chain members, SCM (including information sharing, shared risks and rewards, cooperation, integration of key processes, long-term relationships and inter-functional coordination) is argued to lead to certain positive effects such as lower costs, improved customer value and competitive advantage (Mentzer et al., 2001). When SCM is in place it can be said to consist of three closely interrelated elements (Lambert and Cooper, 2000): the supply chain network structure (the member 
firms and the links between them), the supply chain business processes (key processes and activities that are managed across the supply chain), and the supply chain management components (managerial variables that are integrated across the supply chain).

\section{Third-party logistics}

As the construction industry is approaching SCM, managing logistics is at the core of such initiatives (Hamzeh et al., 2007). CSCMP defines logistics management as "that part of supply chain management that plans, implements, and controls the efficient, effective forward and reverse flow and storage of goods, services and related information between the point of origin and the point of consumption in order to meet customers' requirements” (CSCMP, 2013). This implicitly means that logistics is part of SCM and that the management of logistics activities is a part of SCM. Larson and Halldorsson (2004) call this the "unionist perspective": logistics management is a part of SCM, but managing logistics does not mean that the company also realizes SCM in full.

During the last decades there has been a surge of academic interest and publications in a certain area of logistics management (Selviaridis and Spring, 2007): so called thirdparty logistics (TPL). There has also been a steadily increasing number of companies across industry sectors that use TPL providers for the management of all, or part of, their logistics operations (Marasco, 2008). Marasco (2008) defines TPL as “an external organization that performs all or part of a company’s logistics function”, and Selviaridis and Spring (2007) add to this that TPL is usually associated with the offering of multiple, bundle services, rather than just isolated transport or warehousing functions. TPL arrangements are also based on formal contractual relations, as opposed to spot purchases of logistics services (Lai et al., 2004). TPL can include services such as transport, 
warehousing, inventory management (e.g. materials handling, repackaging), valueadding activities (e.g. secondary assembly, installation of products), information related activities (e.g. tracking and tracing, distribution planning), as well as design and reengineering of the supply chain (Hertz and Alfredsson, 2003; van Laarhoven et al., 2000). TPL is also known as logistics alliances, logistics partnerships, logistics service providers (Skjoett-Larsen, 2000), and in recent years the term fourth party logistics (4PL) has also emerged to describe more advanced arrangements (Selviaridis and Spring, 2007). These more advanced arrangements typically focus more on the managerial, planning and strategic aspects of logistics, thereby being closer to SCM than to "pure" logistics management. TPL as addressed in this research concerns the logistics management part of SCM, although sometimes referred to as SCM in the construction management literature (e.g. Vrijhoef and Koskela, 2000).

\section{Driving forces and concerns with TPL}

Successful implementation of SCM is typically regarded to lead to a number of positive consequences such as lower costs, improved customer value and satisfaction, and competitive advantage (Mentzer et al., 2001). TPL, addressing the logistics management part of SCM, naturally strives towards the same goals. TPL addresses many of the same issues as SCM in terms of dealing with relationships in the supply chain network, addressing certain supply chain processes and management components (Lambert and Cooper, 2000). A literature review reveals that there are a set of driving forces for implementing TPL, but also a set of concerns. These are summarized in Table 1, using Selviaridis' and Spring's (2007) division between strategy-, finance- and operationsrelated issues as a mean for categorizing the issues. Liu and Lyons (2011) concludes in their survey that there is a remarkable consistency on key aspects when evaluating TPL 
and TPL providers, something which Aguezzoul's (2014) survey verifies. Our survey of drivers and barriers also shows consistency on issues that are frequently mentioned in the broad surveys and literature reviews on which our review is based upon (cf. Table 1).

Table 1 - Identified driving forces for and concerns with implementing TPL.

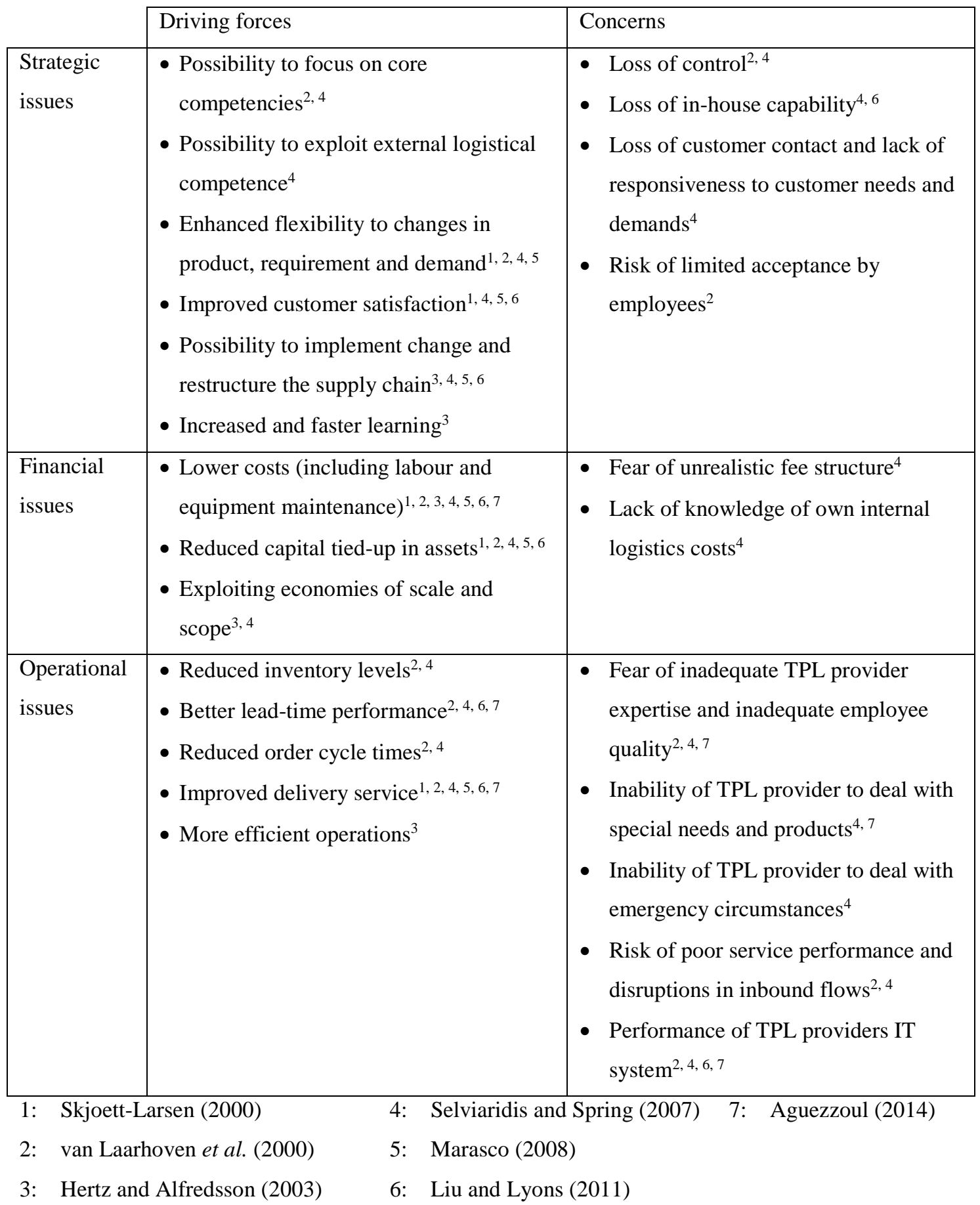


Studying TPL relations over time, van Laarhoven et al. (2000) conclude that once the partnership is implemented many of the concerns inevitably decline, whereas IT and service quality concerns are still present when TPL is up and running. Also Selviaridis and Spring (2007) notice an ongoing dissatisfaction with the TPL providers' IT capabilities. van Laarhoven et al. (2000) however conclude that the renewal rate for TPL contracts is high (indicating that most companies were satisfied with the TPL solution) and that substantial cost reductions and service improvements could be attributed to the TPL partnership, although the companies found it hard to quantify these improvements. It has also been shown that long-term TPL arrangements, with higher levels of commitment and integration, also improve the performance of the TPL provider itself, thereby eliminating or reducing many of the identified concerns (Marasco, 2008). As for the drivers Aguezzoul (2014) notice that cost-related issues are most frequently cited as a driver, followed by service-related issues. Issues relating to relationships are the most frequently mentioned concerns (Aguezzoul, 2014).

\section{TPL in construction}

The construction supply chain, from factory and retailers to the construction site, resembles traditional logistics in terms of structure and implementation, taking the temporary nature and the possible remote geographical location of sites apart. Differences are found in agreements, notifications and general demands on transports. On the construction site the differences are more significant compared to other industries. The geographical positions of the construction sites and the changing site layout put demand on adapted solutions for unloading, inspection of incoming materials and storage (Larsson et al., 2008; Lindén and Josephson, 2013). Delivery and handling of construction 
materials have to be coordinated with site resources such as subcontractors' machines and scaffolding. In this coordination, the return flows of waste and excess materials have to be considered as well (Agapiou et al., 1998). Hence, a lot of effort must be devoted to coordinating the fragmented operations, sourcing materials and resources to the construction site, coordinating materials and resources on the construction site itself, and coordinating return flows from the site. In other words: the management of the construction logistics. A case study by Agapiou et al. (1998) shows that logistics management is relevant in the construction industry and that total costs can be lowered if logistics is managed efficiently. The cost savings reported in Agapiou et al. (1998) constitutes $5 \%$ of the total costs, mainly based on reduction in materials wastage and in working days.

Although construction companies view SCM as a tool to improve coordination with suppliers and subcontractors involved in construction projects (Segerstedt and Olofsson, 2010), the construction industry is still lagging behind in terms of implementing supply chain practices and reap the benefits from better managed supply chains (Bankvall et al., 2010). Therefore some actors in the industry have turned to third parties to improve the logistics management. In the construction industry, many activities are typically outsourced to different consultants and subcontractors (Miller et al., 2002). However, the handling of materials on construction sites is traditionally kept in-house, carried out by the construction workers. In a study by Strandberg and Josephson (2005) construction workers spent around $20 \%$ of their working time moving materials and equipment to the assembly area. Sobotka and Czarnigowska (2005) notice that by outsourcing the logistics processes, such as handling the material, costs can be reduced. This was explained by the fact that by keeping the contractors own transports and storage at minimum, and let logistics professionals manage the logistics, costs were reduced. 
Lindén and Josephson (2013) studied a TPL company in three different construction projects and compared it to a benchmark project were construction workers handled the materials. In most cases the TPL company handled the materials after regular working hours. The advantages were the possibility to use already existing equipment and reduction of construction work disturbances. The conclusion was that outsourced materials handling was advantageous compared to in-house handling of materials and the projects using the TPL solution had lower total costs than the benchmark project. Also, the number of disturbances was lower when the TPL solution was used. Even though the costs for handling the materials outweigh the costs the outsourcing implies, there is hard to draw general conclusions without further research on the topic. This is due to that the contractors are unaware of the hidden costs of logistics handling.

Effective management of the supply chain is identified as a main driver for a more efficient and productive construction industry in "Rethinking Construction” (Egan, 1998), where also the construction clients are emphasized as drivers for change due to their nature as initiators and investors in construction projects. The client's influence on logistics management in the supply chain is mainly by the way that the project is “configured” through the client's choice of procurement strategy and forms of contracts, which determine responsibilities and authorities in the entire construction process. This in turn affects the degree of integration and cooperation among project participants (Briscoe et al., 2004; Eriksson and Westerberg, 2011; Love et al., 1998). The contract configuration also determines the main responsibility for governance among the actors involved in the construction supply chain (Winch, 2001), wherefore the construction clients have a crucial and key role in the implementation of logistics innovation, such as TPL, in the construction industry (Briscoe et al., 2004). 


\section{Summary and research motivation}

To summarize, the construction supply chain is fragmented (Eriksson, 2010) and temporary (Behera et al., 2015), and the low levels of productivity (Abdel-Wahab and Vogl, 2011; Fulford and Standing, 2014) indicate that there is a need for effective management of supply chains in the construction industry (Bankvall et al., 2010). The construction industry has also moved towards SCM in many aspects during the last decades, but the industry still has a long way to go until the practices of SCM are standard (Bankvall et al., 2010). As a first step along this path, construction companies could preferably direct their efforts towards logistics management, possibly taking advantage of the knowledge from TPL providers.

In terms of supply chain network structure (Lambert and Cooper, 2000), Bask (2001) conceives TPL as a set of dyadic relationships between seller/supplier, buyer/customer and logistics service providers in a supply chain, requiring changes in both organization and information systems (Skjoett-Larsen, 2000). Hence, TPL also affects the supply chain business processes and the supply chain management components (Lambert and Cooper, 2000). In Selviaridis’ and Spring’s (2007) literature review on TPL, covering the years between 1990-2005 including 114 academic sources, it is concluded that almost all research has focused on the firm or dyadic level, whereas only $6 \%$ of the research was on the network level (three or more entities). The more recent literature review by Aguezzoul (2014) covering 67 articles between 1994-2013 does not show any significant changes in research focus during the last decade. Hence, in that sense very little of the TPL research has focused on a supply chain setting, following the definition that a supply chain is made up of at least three or more entities (Mentzer et al., 2001). Selviaridis and Spring (2007) therefore also propose a greater focus on the "network" level for future TPL research, especially including enablers (i.e. driving forces) and inhibitors (i.e. 
concerns) regarding the design and implementation of TPL. Furthermore, they also call for an empirical examination of TPL providers as supply chain integrators, a request also supported by Fabbe-Costes et al. (2009). Besides this, Selviaridis and Spring (2007) also see a need for more empirical research in TPL (focusing on design and implementation) and on qualitative research methods, such as case studies, to gain a deeper understanding (Flyvbjerg, 2006) of the formation and evolution of TPL relationships. The results from the study by Liu and Lyons (2011) shows that there still has been relatively little attention given to empirical studies of TPL.

Our research takes a stance in the gaps identified above. It covers a TPL setting on the network level going beyond the dyadic relationships and focus on a supply chain setting including three entities (client, contractors and TPL provider). Furthermore, the research focuses on the empirical examination of the design and implementation of TPL using a case study. Even though the research is explorative, there is also an attempt to understand the relationships between the involved entities and the realized effects of the TPL solution for the involved parties.

\section{Case study}

\section{Project background}

The university hospital in Linköping, Sweden, currently has major ongoing construction works with new buildings being built as well as existing being refurbished. The project has a total budget of close to $€ 430$ million and a time plan of ten years. The construction site is situated in connection with the existing hospital; wherefore there are high demands on that the construction process should not disturb the ongoing operations in and around the hospital. The project is divided into three stages, of which the first is in focus in this study. The first stage is the largest one with a budget of €300 million and consists of 
erection of four new buildings in connection to the existing buildings, one to the west, one to the east, a multi-storey car park and a new building for the university in connection with the north entrance, see Figure 2. In total the new buildings constitute 66,000 square meters and in peak periods around 550 persons are working at the site. During this first stage the estimated number of deliveries is approximately 60,000 , or roughly $40-45$ per day, as an example of the project's magnitude when it comes to logistics. Due to the large amount of deliveries and the complex environment with a fully operative hospital, the client decided to use a TPL provider specialized towards the construction industry for handling all the logistics and for materials handling at the construction site. The second stage of the construction project consists of refurbishment of existing buildings and the third stage consists of a new building for psychiatric care, but none of them are studied in this research. 


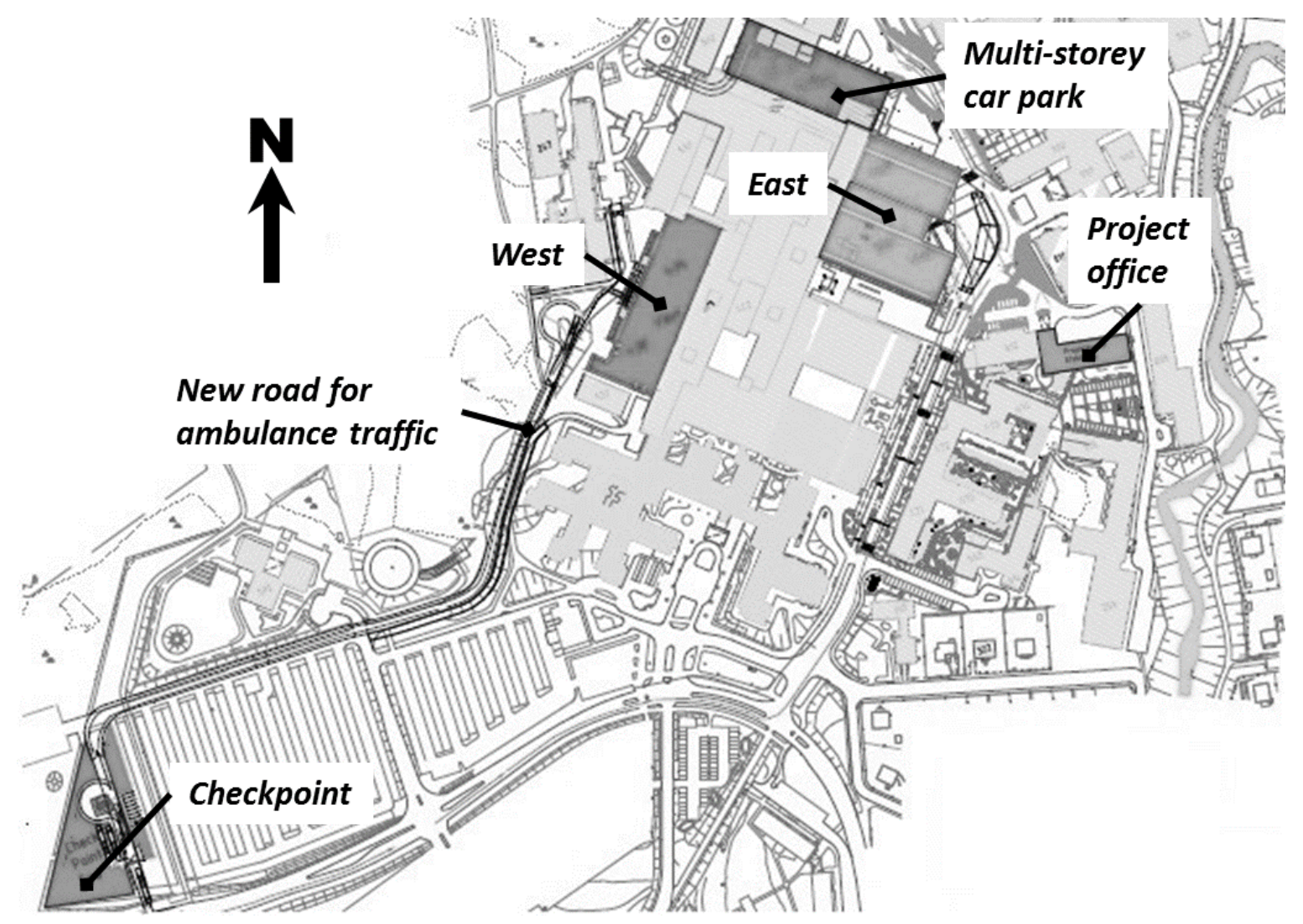

Figure 2 - The construction site with the checkpoint, transport routes and the new buildings.

The first stage of the project is divided in to two main parts. The first part concerns the erection of the loadbearing structure and the climate screen (e.g. windows and roof). The second part consists of structure completion (e.g. inner walls, installations, electricity and so on). The main contractor together with a loadbearing contractor has the responsibility for erecting the loadbearing structure and the climate screen. The structure completion is divided into several contracts; each contract includes responsibility for the completion of one floor level. In Figure 3 an overview of the organizational structure can be viewed, indicating contractual bonds as well as coordinating bonds between the different parties in the construction project. The main contractor has the responsibility to coordinate all subcontractors in line with the client's requirements and with the hospital operations. The main contractor is also responsible for budget and time plan for the entire project, 
according to a partnering agreement with the client. All the subcontractors except a few are, however, procured by the client and are organizationally situated under the client's project management.

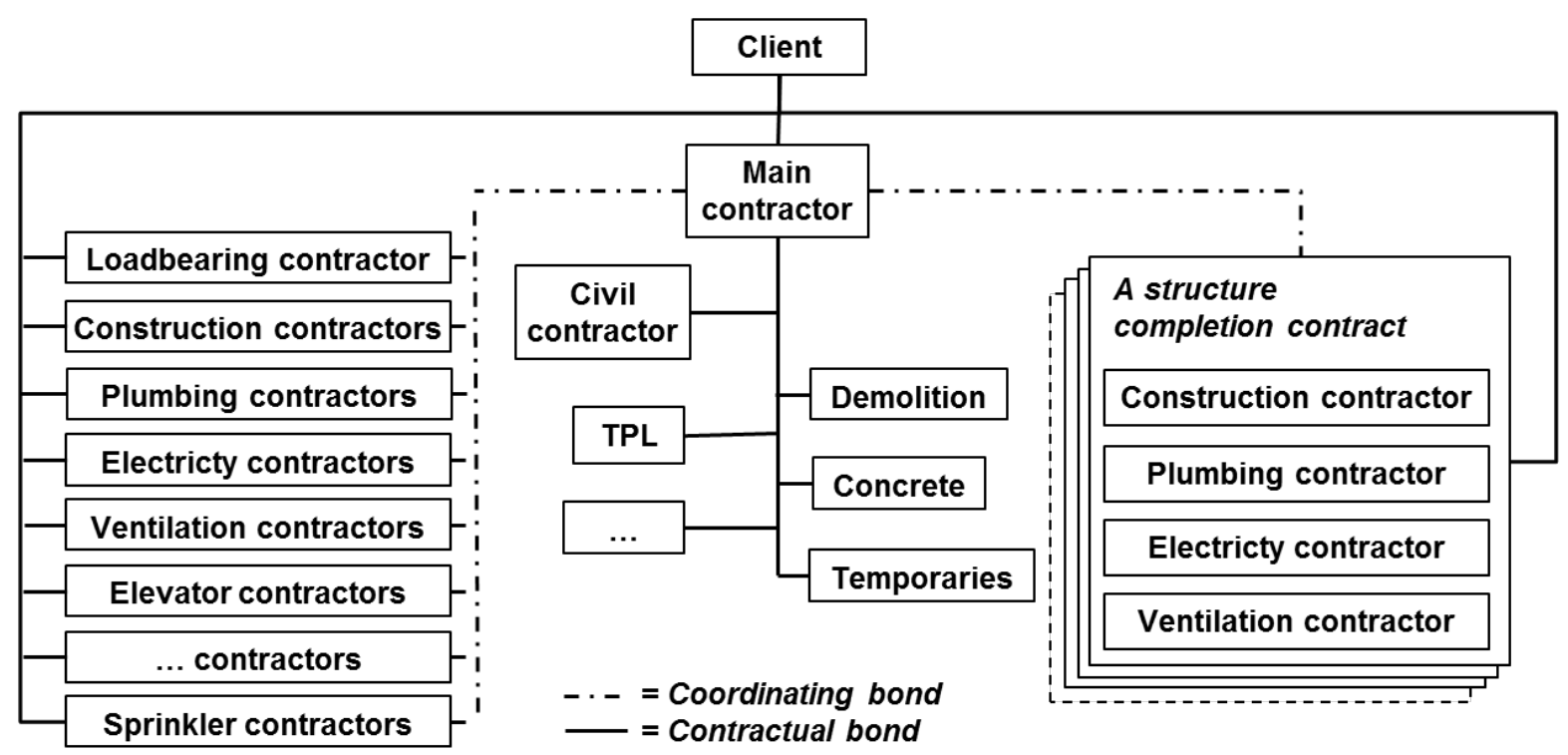

Figure 3 - The organizational structure for the construction project. Solid lines indicating contractual bonds, dotted lines indicating bonds coordinated by the main contractor.

The TPL setup

Organizationally the TPL provider is situated under the main contractor (see Figure 3), who also procured the TPL provider according to the client's directives. The setup with a TPL provider responsible for coordinating all the materials and equipment necessary for the construction work was decided upon by the client and stated in the procurement process, thereby known to all contractors entering the project. The TPL provider has stated a number of regulations on deliveries, sizes and weights of pallets and arriving materials, as well as maximum levels of materials stored on site. The contractors are informed about the regulations in a leaflet that is updated throughout the construction 
project, and in weekly meetings organized the TPL provider. The TPL provider is also responsible for the construction site disposition plan, planning and placements of scaffolding, temporary construction elevators, tower cranes and mobile cranes used during the construction project. To avert the traffic induced by deliveries and keep them from disturbing the hospital operations and ambulance traffic, all deliveries are destined to a checkpoint (see Figure 2), and deliveries are planned in an online planning tool coordinated by the TPL provider. Gate keepers posted around the construction site makes sure that no deliveries enter without permission and that no ambulances are hindered. A new road for ambulance traffic has also been constructed south west of the hospital, parallel to the access road for material deliveries (see Figure 2).

Below the TPL setup will be described in more detail following the logic of the SCM framework in Lambert and Cooper (2000); describing the supply chain network, the supply chain business processes and the supply chain management components.

\section{The supply chain network}

In Figure 4 the principal supply chain network serving the construction project can be viewed. There are several different contractors involved (see Figure 3), active in different stages of the construction project, whose job is to deliver the buildings to the client. Each contractor has one or several suppliers who will deliver material to the contractors by the use of transport providers. One supplier may be used by only one contractor, but most of the contractors use the same suppliers. The transport providers also differ, some are large transport providers used by several suppliers and some are smaller haulers used by only one supplier. Some suppliers even distribute their own materials with own trucks. Since all the materials arriving at the construction site are handled by the TPL provider they become the focal company of the supply chain network in this study, resembling the role 
of a supply chain integrator (Fabbe-Costes et al., 2009) and a materials coordinator (Agapiou et al., 1998).

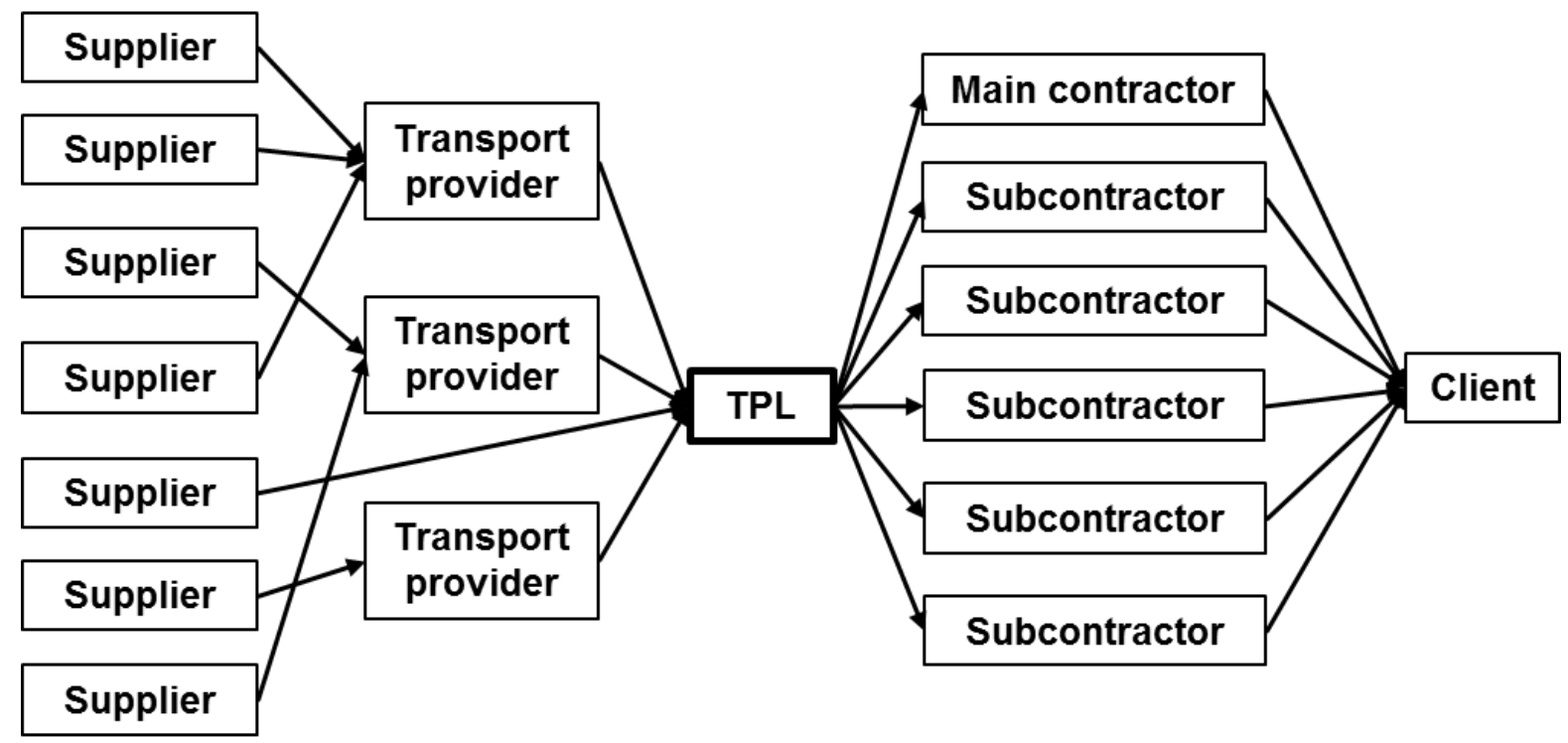

Figure 4 - The supply chain from suppliers to client, with the TPL provider as the focal company in the middle.

Supply chain business processes

Lambert and Cooper (2000) identify a set of supply chain processes of which some regards the logistics management part of SCM. In this study the following processes relates and are affected by the TPL solution: the materials flow process, the delivery planning process, and the materials return flow process. These processes are described in the following.

In terms of material flow processes, the contractors order materials from their suppliers that are delivered by transport providers, typically procured by the suppliers. It is possible to identify two types of material flow processes. First there are direct deliveries where the contractors themselves are responsible for inspection and handling of the material after 
arrival. This type of deliveries arrive during daytime and typically consist of concrete reinforcements, prefabricated concrete elements and special deliveries that have allowance to be delivered during daytime. Even though they are direct deliveries, slot times must be booked and all deliveries must go through the checkpoint. For the direct deliveries, a notification is sent to the contractors at the construction site after clearance is given by the gate keepers. All these activities are managed and controlled by the TPL provider.

The second material flow process, which is the most common one, concerns material flows where the TPL provider handles and inspects the arriving material as well as unloads incoming deliveries. These deliveries are only allowed to arrive between $4 \mathrm{pm}$ and midnight. When a delivery arrives at the checkpoint the personnel from the TPL provider makes an acceptance inspection, making sure who has ordered it, where it is from, that the delivery is on time, the number of pallets and in what condition the arriving pallets are. After clearance, the arriving truck is sent to the construction site to be unloaded by the TPL provider. The TPL provider also delivers the material to the contractor's work stations, where after a notification goes directly to the contractor who placed the order. Unplanned, late or early deliveries are only allowed to enter if there is an available slot in the booking system.

The delivery planning process is based on a prescribed set of steps for ordering, booking and delivering materials to the construction project (see Figure 5). This is also complemented by weekly meetings between the TPL provider and all the contractors at site. The planning process in itself is facilitated by the aid of an online planning tool, helping the contractors to coordinate incoming deliveries. All incoming deliveries (orders) have to be booked no later than five days prior to arrival (1 and 2 in Figure 5). The five day limit is needed in order for the TPL provider to plan their work, but also for 
forcing the contractors to plan ahead and for avoiding “emergency orders”. The online planning tool has a graphic calendar interface in which the contractors can identify empty time slots for the upcoming weeks. When a contractor books a time slot, it is up to the contractor that book to decide on when a delivery is to arrive and how long time that is needed for unloading. The contractor also has to mark what type of material flow process that the order concerns (i.e. direct delivery or deliveries handled fully by the TPL provider). If it is the second type of material flow process, the contractor also needs to state when the material is to be delivered to the contractor's work station by the TPL provider. The contractor also enters the number of pallets, size and weight of pallets, and what resources, such as forklifts or cranes, that will be needed for unloading. All bookings are controlled and acknowledged by the TPL provider. When the booking is acknowledged, an e-mail notifies the contractor about the details. Neither the suppliers nor the transport providers have access to the online planning tool. Thus, it is the contractors' responsibility to inform their suppliers what time slot they have booked, so that they in turn can plan the shipment of the goods needed.

When a delivery (4 in Figure 5) is within 30 minutes from the checkpoint the driver contacts the personnel at the checkpoint to notify about the arrival (3 in Figure 5). The notification is crucial because it gives the personnel at the checkpoint the opportunity to hold up incoming deliveries if there is any type of disturbance (e.g. a halt in production or an incoming ambulance) and they are able to avoid queues of large trucks causing traffic jams. Since the drivers generally are on the freeway when they get in touch, they are able to stop at gas stations and wait to be directed to the checkpoint.

So far (1-4 in Figure 5) the delivery planning process is the same for both types of material flow processes. Concerning direct delivery, the planning process for the TPL provider ends with directing the truck to the designated place for unloading (5a in Figure 
5) and notifying the contractor that the delivery has arrived and been cleared at the checkpoint (6 in Figure 5).

For the second type of material flow process, the TPL provider also handles the unloading, the delivery to the work stations, and the preparation of materials ( $5 \mathrm{~b}$ in Figure 5). When the material is ready to use at contractors' work stations, a notification (6 in Figure 5) is sent to the contractors. The notifications include a discrepancy report containing photographs and other additional information. The contractor then has one day to inspect the material and make any complaints.

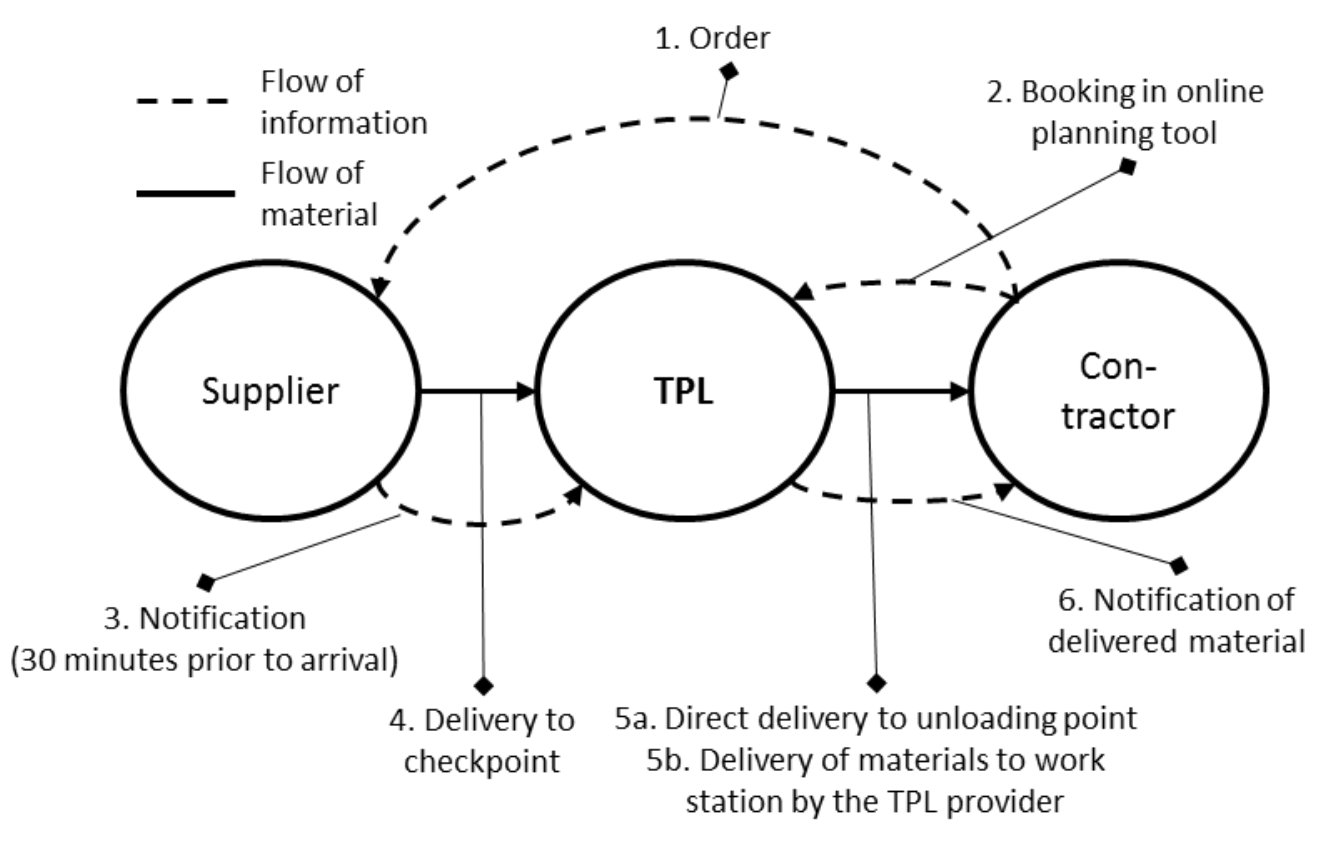

Figure 5 - The prescribed process of ordering, booking and delivering materials to the construction project. The numbers indicate in which order the activities occur.

Figure 4 and Figure 5 only show the supply chain network of materials arriving to the construction site. However, naturally there is a return flow of materials as well. Return flows, including waste, is handled by a large recycling company. There are waste bins for 
different kinds of waste (e.g. wood, plasterboards, metal, etc.) at every floor level for the contractors to use. The waste bins are collected and emptied in the early mornings. Although the materials return flow process is coordinated with the other supply chain processes by the TPL provider, the actual process is not carried out by the TPL provider. Hence, the materials return flow process is left out of scope in this study.

\section{Supply chain management components}

During the construction project all materials necessary for the construction work and equipment necessary for the materials handling on site is coordinated by the TPL provider. The TPL provider is also responsible for the delivery planning, the resources booking and the materials delivery to, and at, the site during off-hours. However, the TPL provider does not have any contact with the suppliers or any other upstream tier. The only exception is the transport providers' drivers when they arrive at the checkpoint, and hence have direct contact with personnel from the TPL provider. It is up to the contractors to order materials and keep contact with their suppliers.

The regulations on materials handling and logistics on the construction site is the main tool that the TPL provider uses to coordinate the site logistics. The regulations are clearly stipulated in an information leaflet that is updated continually as the construction project progress. Beside guidelines on sizes and weights of pallets there are also regulations on how materials are to be loaded on trucks, labelled and packaged, in order for the TPL provider to easily unload them. During daytime construction elevators are only allowed for personnel transport and not to be used for transporting materials. Furthermore, the tower cranes are not allowed to lift materials needed for structure completion. Every day the contractors need to make sure that access routes on each floor level are clear so that forklifts and pallets may come through. The contractors have to keep their work stations 
in order and no storage of materials other than for immediate production is allowed at work stations on site.

Once a week the TPL provider and the contractors have a meeting to plan the coming week's deliveries in detail and check that the reserved slots in the online planning tool are accurate. The main contractor, one representative from each structure completion contract and contractors with planned incoming deliveries are required to participate. The meetings also address general problems that have occurred since last meeting. Each floor level is discussed and the appointed storage locations available for incoming deliveries are determined as well as changes in previous plans.

The TPL solution is mandatory for all of the contractors to use and the material flow process up to the checkpoint is free of charge for the contractors. However, for providing the service of unloading and the handling of the materials provided, the TPL provider charges the contractors a fee per pallet, which varies between different types of pallets (e.g. standard euro pallet, heavy pallet, pallet up to 6 meters long, etc.). Forklifts are included in the fee the contractors have to pay while cost for the crane, including crane operator, are charged extra. The fees are listed in the information leaflet and known to the contractors. The contractors will also have to pay penalties if not access routes and work stations are in order and obstruct the TPL provider when handling material. The TPL provider also charges the contractors for unused resources if planned deliveries do not arrive.

\section{Case analysis}

The realized and potential effects from using a TPL solution are analysed using Selviaridis' and Spring's (2007) division between strategic, financial and operational issues and are summarized in Table 2 (also confer the summary of the literature review 
in Table 1). Some of the driving forces and concerns in Table 1 are verified in this case, others are not verified and some new ones, not identified in the literature review, have been identified.

\section{Strategic issues}

Starting with the verified issues, both the client and the hospital have expressed a high satisfaction with how the TPL solution has turned out (i.e. improved customer satisfaction). The possibility to exploit external logistical competence was identified as a driving force in Table 1 and has been verified in this study. This has also enabled the contractors to focus more on their core competences when delivery planning and materials handling have been managed by the TPL provider. The TPL provider emphasize in the information leaflet that the TPL solution will free time for value adding work tasks. This has been confirmed by the contractors: they can focus on the construction tasks, their core competencies, instead of waiting for deliveries and handling materials. On the downside concerning strategic issues is the fact that there has been a lot of negative attitudes towards the TPL solution among the contractors, especially among those that have not utilized the materials handling services. It has also been noted a limited acceptance among the employees at the construction site, especially in the early phases of the project.

The main reason why the client decided to use a TPL solution was because of the critical criteria that no ambulance traffic was to be disturbed. The result has been good and so far only one incident has occurred that delayed an ambulance. In that sense the TPL solution can be seen as a facilitator for the construction project for not interfering with hospital operations, which is considered a new strategic issue. The external logistical competence of the TPL provider has also enabled the project to focus on the construction 
site, while handling the supply chain by clear regulations for optimizing logistics. As such a clear interface with upstream tiers of the supply chain has been established (something Vrijhoef and Koskela (2000) label "the first role of SCM in construction”). Finally, all contractors acknowledge the importance of the TPL solution in large projects, some even meaning that it is a prerequisite, or a necessity, in large projects.

Turning to the new barriers identified in the study, managers at the contractors have found it hard to follow budgets and time plans. The budgets and time plans are made in early phases, before the construction work has begun, and is typically done by central planners that do not work operationally within the project. Thereby the TPL solution had to be accounted for in early planning, which was not always done, possibly leading to unrealistic budgets and plans. This is a concern rooted in the lack of experience of working with a TPL solution, as well as how budgets and time plans are traditionally prepared in the industry. Furthermore, the organizational setup of the construction project, with the TPL provider positioned under the main contractor, (see Figure 3) has not been optimal. The TPL provider would have had more leverage on the contractors that neglected the logistics solution if they were positioned under the client's project management. The main contractor also neglected the TPL setup and the agreements surrounding it and planned their deliveries irrespectively of the delivery planning system, putting the TPL in a cumbersome position. Finally, the contractors perceive that the suppliers are negative towards the TPL solution, not used to specific demands on what time to deliver, especially after ordinary work hours. Some problems that are highlighted are that it can be hard for suppliers to co-load deliveries because of the contractors' different working pace and, in this particular case, the lack of a terminal for interim storage and cross docking. Hence, there has been a lack of focus on upstream tiers in the 
supply chain. However, the larger suppliers have had start up meetings with the TPL provider to learn about the logistics solution.

Table 2 also displays a number of strategic issues that have not been verified in this study. This does however not mean that they are non-existing in construction, but that they have not been identified in this single case study.

\section{Financial issues}

By delivering the material during evenings the utilization of the construction site has been prolonged, instead of that it closes down when the construction workers leave for the day. This has also increased the utilization of equipment such as scaffolding, construction elevators and cranes. The TPL provider was also able to reduce the number of elevators since construction workers and materials handling are kept apart, which also has a positive effect on the construction workers' working environment. The contractors also state that they have reduced the unit times, on which estimates for time schedules, needed resources and costs are calculated, and reduced the number of construction workers compared to initial planning. Thereby the case study verifies a reduction in both costs and in capital tied up in resources, as indicated in Table 2.

The hidden costs for logistics and materials handling became transparent when contractors received invoices from the TPL provider and many of the contractors felt that they paid a high price for a service they equally could have done themselves. Yet, when confronted, it was clear that they were unaware of how much the logistics management costs when they perform it themselves. Some of the contractors bypassed the TPL provider and brought in materials by themselves in order to reduce costs from the TPL. The contractors also state that it is hard for them to calculate what the costs are going to be, mainly due to that they are unaware of how many trucks, pallets, etc., that their 
materials requirements will result in. This further enhanced the contractors' impression that the fee structure for the TPL was unrealistic.

The TPL provider in this case study is of the opinion that a terminal for interim storage will only tie up capital in the form of construction materials being stored. By not having a terminal and regulating how much material the contractors are allowed to store on the construction site, tied up capital is limited. Some contractors, mainly the contractors that order materials from abroad with long and partly uncertain delivery lead-times, are negative towards the lack of a terminal and have arranged interim storages of their own to ensure that the material is accessible when needed. Besides this, no new financial issues were identified, and since it was a dedicated TPL solution for one specific project, no real economies of scale or scope could be identified in the case data. This might have been different, however, if a different TPL setup had been employed.

\section{Operational issues}

All of the subcontractors participating in the case study expressed that there have been positive effects in terms of value adding time, since the construction workers have been concentrated on the actual value-adding tasks instead of handling materials. The operations (construction work) have thereby been more efficient with an increase in production pace that has affected time plans positively. A positive aspect with all deliveries destined to a fixed checkpoint was that all drivers learnt where to go for unloading. At most there have been 1-2 deliveries, out of the 150-200 per week, that arrived to the wrong location. The delivery precision has been good, most of the deliveries are accurate, about $70 \%$ have arrived within 15 minutes of the planned time. In summary, the delivery service has been a positive effect of the TPL solution (see Table 2). There were also a number of concerns with the TPL solution that were verified in the study (cf. 
Table 2). The main contractor expressed that they expected the TPL provider to be more competent and take more initiatives to improve operations and the performance of the construction project. There has also been scepticism about the TPL provider's ability to deal with special kinds of deliveries, emergency circumstances, and their ability to perform the work in the way the contractors want.

A new positive effect was that the working environment was considered better. Regulations on materials storage and materials handling carried out by a third party led to better working conditions, both concerning the physical layout and in terms of more focused, and less stressful, working conditions. Furthermore, and contrary to the literature review all the contractors were satisfied with the TPL provider's online planning tool (therefore noted both as a new driver and as a non-verified barrier in Table 2). However, just about $50 \%$ of the deliveries were planned at least five days before arrival, as stipulated, and as much as a third of the arriving deliveries were not planned at all. This affected the TPL provider negatively who could not work according to plan, but rather had to deal with the most urgent tasks. The TPL provider express that the contractors expected flexibility towards the time limit regulations and that the contractors felt that the regulations were too rigid. Furthermore, it was noted a potential risk that the construction workers were being worn out due to monotone work tasks. Even though this was not emphasized as a major issue by any of the subcontractors, case data indicated that this could be a concern when a TPL provider is employed for handling work tasks normally conducted by the construction workers. Yet, the total workload on the construction workers has been reduced thanks to the TPL provider.

The logistics meetings were new to the contractors; therefore, they tended to be short and many preferred to listen passively instead of being active. The contractors stated that they were good and effective, however many contractors, among them the main 
contractors often neglected the meetings. The meetings also dealt with other issues not directly related to logistics, such as heaters and toilets for the different floor plans. These issues were necessary for the progress of the construction works and the logistics meetings became a natural forum to address these questions. 
Table 2 - Potential and realized effects from using a TPL solution in the studied construction

project. Numbers indicating driving forces and concerns similar to the ones found in Table 1.

\begin{tabular}{|c|c|c|c|}
\hline & & \multirow[b]{2}{*}{$\begin{array}{l}\text { - Possibility to focus on core } \\
\text { competencies (including more focus } \\
\text { on activities at the construction } \\
\text { site) }{ }^{2,4} \\
\text { - Possibility to exploit external } \\
\text { logistical competence }{ }^{4} \\
\text { - Improved customer satisfaction }{ }^{1,4,5} \\
6\end{array}$} & Concerns/Barriers \\
\hline \multirow{3}{*}{ 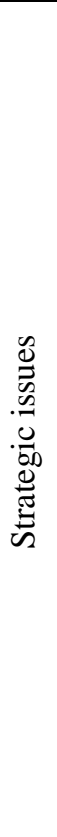 } & Verified & & $\begin{array}{l}\text { - Risk of limited acceptance by } \\
\text { employees }{ }^{2}\end{array}$ \\
\hline & New & $\begin{array}{l}\text { - Not interfering with third-party (i.e. } \\
\text { the hospital in this case study) } \\
\text { - Establishing interface between } \\
\text { construction site and supply chain } \\
\text { - Necessity in large projects }\end{array}$ & $\begin{array}{l}\text { - The TPL solution has to be considered } \\
\text { in early planning } \\
\text { - Lack of experience with TPL solutions } \\
\text { - The TPL providers position in the } \\
\text { organization } \\
\text { - Risk of not focusing on the upstream } \\
\text { tiers }\end{array}$ \\
\hline & $\begin{array}{l}\text { Not } \\
\text { verified }\end{array}$ & $\begin{array}{l}\text { - Enhanced flexibility to changes in } \\
\text { product, requirement and } \\
\text { demand }{ }^{1,2,4,5} \\
\text { - Possibility to implement change and } \\
\text { restructure the supply chain }{ }^{3,4,5,6}\end{array}$ & $\begin{array}{l}\text { - Loss of control }{ }^{2,4} \\
\text { - Loss of in-house capability }{ }^{4,6} \\
\text { - Loss of customer contact and lack of } \\
\text { responsiveness to customer needs and } \\
\text { demands }^{4}\end{array}$ \\
\hline \multirow{3}{*}{ 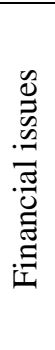 } & Verified & $\begin{array}{l}\text { - Lower costs (including labour and } \\
\text { reduced and better utilized } \\
\text { equipment) }{ }^{1,2,3,4,5,6,7} \\
\text { - Reduced capital tied-up in assets } \\
4,5,6\end{array}$ & $\begin{array}{l}\text { - Fear of unrealistic fee structure } \\
\text { - Lack of knowledge of own internal } \\
\text { logistics costs }\end{array}$ \\
\hline & New & None identified & None identified \\
\hline & $\begin{array}{l}\text { Not } \\
\text { verified }\end{array}$ & $\begin{array}{l}\text { - Exploiting economies of scale and } \\
\text { scope }^{3,4}\end{array}$ & None identified \\
\hline \multirow{3}{*}{ 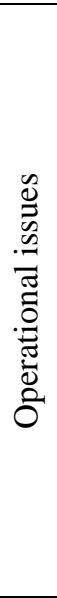 } & Verified & $\begin{array}{ll}\text { - } & \text { Reduced inventory levels } \\
\text { - } & \text { Better lead-time performance } \\
\text { - } & \text { Improved 6, } 7 \\
\text { - } & \text { More efficient operations } \\
\end{array}$ & $\begin{array}{l}\text { - Fear of inadequate TPL provider } \\
\text { expertise and inadequate employee } \\
\text { quality }{ }^{2,4,7} \\
\text { - Inability of TPL provider to deal with } \\
\text { special needs and products } 4 \\
\text { - Inability of TPL provider to deal with } \\
\text { emergency circumstances } \\
\text { - Risk of poor service performance and } \\
\text { disruptions in inbound flows } \\
\text { 2,4 }\end{array}$ \\
\hline & New & $\begin{array}{l}\text { - Performance of TPL provider’s IT } \\
\text { system } \\
\text { - Better working environment }\end{array}$ & $\begin{array}{l}\text { - Monotone work } \\
\text { - TPL provider pinioned by contractors } \\
\text { not following regulations }\end{array}$ \\
\hline & $\begin{array}{l}\text { Not } \\
\text { verified }\end{array}$ & - Reduced order cycle times ${ }^{2,4}$ & $\begin{array}{l}\text { - Performance of TPL providers IT } \\
\text { system }{ }^{2,4,6,7}\end{array}$ \\
\hline \multicolumn{4}{|c|}{$\begin{array}{llllll}\text { 1: } & \text { Skjoett-Larsen (2000) } & \text { 4: } & \text { Selviaridis and Spring (2007) } & \text { 7: } & \text { Aguezzoul (2014) } \\
\text { 2: } & \text { van Laarhoven } \text { et al. (2000) } & \text { 5: } & \text { Marasco (2008) } & & \\
\text { 3: } & \text { Hertz and Alfredsson (2003) } & \text { 6: } & \text { Liu and Lyons (2011) } & \end{array}$} \\
\hline
\end{tabular}




\section{Discussion}

There are three focal actors in this study: the client, the TPL provider and the contractors, of which the main contractor naturally is the most important. The client has shown commitment to solving logistical concerns by initiating the TPL solution, but has then forced the responsibility on to the main contractor, that in this case has been reluctant to the TPL solution and thereby partly limiting the leverage of the TPL solution. Despite that logistics and materials handling have been seen as crucial for the construction project from the beginning, no expertise on logistics can be found in the client's project management team. One interpretation is that instead of seeing the TPL solution as a strategic tool for creating competitive advantage through increased service and flexibility (Skjoett-Larsen, 2000), the client viewed the TPL solution as a way to buy themselves free of addressing logistics management issues. Even though this critique mainly falls back on the client, also the contractors and even the TPL provider could have acted differently.

The contractors in this study were conservative and did not see the possible benefits of the TPL solution, rather they focused on the costs for the TPL services. The main contractor, responsible for coordinating the entire project, restrained the TPL provider by not following agreements and regulations. This also sends a message to the subcontractors that the agreements and regulations concerning the TPL solution are not that important. This contradicts many of the key issues for successful TPL solutions identified by van Laarhoven et al. (2000), such as top management engagement and close, dedicated working relationship between the main actors.

The TPL provider only focused on the construction site, despite that their regulations affected the suppliers and transport providers more than the contractors. The contractors found it hard to understand why some of the regulations exist, which can explain some of 
their negative attitudes towards the TPL solution. The contractors also found it hard to interact with the suppliers and have to explain to them the regulations on how to load and pack materials. Instead it would have been better if the TPL provider, who has set the regulations, would interact directly with the suppliers and transport providers. Well defined requirements, procedures and systems have been identified as important factors when implementing TPL (van Laarhoven et al. (2000), but without also investing in human capital and a change of attitudes, the TPL arrangement might fail, or at least not deliver its full potential (Skjoett-Larsen, 2000). The TPL provider in this case mainly focused on setting regulations and requirements, but underestimated the need for education and change of attitudes. The TPL provider also failed in seeing themselves as a service function for the entire supply chain, that it is their competence that is sought after and that the TPL solution is not a purpose of its own. In that sense, interdependencies and interfaces along the supply chain must be taken into account in the TPL solution (Selviaridis and Spring, 2007), and not just the interface between the construction site and the supply chain.

By using a TPL provider, a structured interface between the supply chain and the construction site is established, which is in line with the first role of SCM in construction described by Vrijhoef and Koskela (2000). In this case study a large focus among the companies has been on the construction site. That is a natural focus for many of the participating companies, mainly working on the construction site, with the final product in focus. Focusing on the construction site is not wrong. On the contrary, in order for the supply chain to interact with the construction site there has to be improvements concerning logistics management at the construction site. Therefore, a focus on the construction site can be interpreted as a fifth role of SCM in construction (cf. Vrijhoef and Koskela (2000) “The four roles of SCM in construction”). However, the project and 
the participating companies tend to get stuck in details of site operations and their focus do not stretch further than the limits of the construction site. In order to obtain the second, third and finally the fourth role (Vrijhoef and Koskela, 2000), they need to extend their focus to the entire supply chain and as such address the issues that constitute SCO.

A TPL solution is a good tool that has a good number of positive effects on logistics if used properly and addressing the concerns and barriers. The positive effects may spur participating companies to think about other parts of SCM than logistics. In all the interviews there was an understanding of that efficient construction is dependent on effective SCM and logistics. There was also an understanding of the need for change in the construction industry. However, a TPL solution is not a replacement for addressing issues necessary to implement SCM. A TPL solution is best used as a tool in a SCM initiative, but it does not replace the need for SCM in the construction industry. To realize SCM, the construction industry needs to challenge the traditional way of managing logistics.

\section{Conclusions and future research}

This single case study together with the literature review focusing on TPL, but also taking SCM and the construction industry context into account, provided insights on the new phenomenon of TPL providers managing logistics in the construction industry. Based on the literature review, the main driving forces and concerns of using a TPL solution are listed in Table 1, answering the first research question. Even though TPL has been used in different industry settings, showing similar sets of driving forces and concerns (Langley, 2015), there is still a need to investigating whether these factors also are valid for the construction industry. By performing a single case study of a large construction project in which a TPL solution was used, it was possible to map the potential and realized 
effects of a TPL solution as a new phenomenon in the construction industry and to contrast these with the findings from the literature review. Some of the driving forces and concerns from the literature review were verified to exist also in the setting of a large construction project, while other effects could not be verified. However, since it is a single case study and as such has limited generalizability, it is too early to state that they do not exist in construction. More studies are needed to verify this. Some of the identified effects were new, compared to what was found in previous literature, indicating that the construction industry context involves new driving forces and concerns compared to other industries. Table 2 lists the potential and realized effects of using a TPL solution in a large construction project, providing an answer to the second research question. The identified driving forces and concerns listed in Table 1 and Table 2 are the first contributions of this study, where Table 2 can be used as a starting point for addressing TPL in construction taking the specifics of the construction industry setting into account. The implementation of a TPL solution in construction will be facilitated by addressing these issues.

This study shows that a TPL solution is an effective tool for dealing with construction site logistics and for establishing an interface between the construction site and the upstream supply chain (the latter labelled as the first role of SCM in (Vrijhoef and Koskela, 2000)). Furthermore, the use of TPL can be a powerful tool for clients to initiate, and have an active role in, the integration of the construction supply chain, in accordance with the reasoning in Briscoe et al. (2004). However, a TPL solution is not a mean to realize SCM in construction, but rather a tool that, when used properly, can help to overcome some of the logistics related problems in the construction industry. It is important to note that the TPL providers have seen the business opportunity in a construction industry where the different parties have been falling behind in terms of logistics performance. As such, it is the competence that the TPL providers hold that the 
construction industry needs, not TPL solutions per se. The insight that TPL solutions are powerful tools, but not a quick fix to realize SCM, is the second contribution of this study, answering research question three. Since TPL solutions are a new phenomenon and new TPL providers will emerge, this insight is needed in order for the construction industry not to take shortcuts in their efforts of implementing SCM, but rather to acquire the necessary knowledge to be able to fully exploit TPL as part of a SCM implementation.

An interesting future research topic would be to study how TPL solutions in the construction industry evolve, as well as how the construction industry adapts to their presence. In the study by van Laarhoven et al. (2000) only $37 \%$ of the TPL relations were regarded as highly successful within four years of operations, whereas $67 \%$ of partnerships older than four years were regarded highly successful. This can be interpreted in many ways, but it indicates that it takes time to reach a highly successful TPL solution. Even though not all TPL solutions were regarded highly successful in the study by van Laarhoven et al. (2000), very few of the respondents seem to have regrets about their decision to employ TPL initiatives. Another topic that needs further research, and that would be a natural next step following this study, is to investigate how the suppliers and transport providers are affected by a TPL solution. A part of this could also be to investigate how supply chain oriented (SCO) the suppliers and transport providers are compared to the contractors, clients and the TPL providers. 


\section{References}

Abdel-Wahab, M and Vogl, B (2011) Trends of productivity growth in the construction industry across europe, us and japan. Construction Management and Economics, 29(6), 635-44.

Agapiou, A, Clausen, L E, Flanagan, R, Norman, G and Notman, D (1998) The role of logistics in the materials flow control process. Construction Management \& Economics, 16(2), 131-7.

Aguezzoul, A (2014) Third-party logistics selection problem: A literature review on criteria and methods. Omega, 49, 69-78.

Bakker, R M (2010) Taking stock of temporary organizational forms: A systematic review and research agenda. International Journal of Management Reviews, 12(4), 466-86.

Bankvall, L, Bygballe, L E, Dubois, A and Jahre, M (2010) Interdependence in supply chains and projects in construction. Supply Chain Management, 15(5), 385-93.

Bask, A H (2001) Relationships among tpl providers and members of supply chains - a strategic perspective. Journal of Business and Industrial Marketing, 16(6-7), 471-86.

Behera, P, Mohanty, R P and Prakash, A (2015) Understanding construction supply chain management. Production Planning \& Control, 26(16), 1332-50.

Borgbrant, J and Apleberger, L (2008) Styrande och stödjande dokument för en effektiv byggprocess samhällsbyggandets kontraktskommitté, Karlskrona: Boverket.

Briscoe, G H, Dainty, A R J, Millett, S J and Neale, R H (2004) Client-led strategies for construction supply chain improvement. Construction Management and Economics, 22(2), 193-201.

Bygballe, L E and Ingemansson, M (2014) The logic of innovation in construction. Industrial Marketing Management, 43(3), 512-24.

Christopher, M (2011) Logistics and supply chain management. 4th ed. Edinburgh Gate: Prentice Hall.

CSCMP (2013), Supply chain management definitions and glossary [Online], Council of Supply Chain Management Professionals (CSCMP), Available: http://bit.ly/1sYBIlP [Accessed: 26th of February 2016].

Department for Business Innovation and Skills (2013) Supply chain analysis into the construction industry - a report for the construction industrial strategy, London: Department for Business Innovation and Skills (BIS).

Dubois, A and Gadde, L-E (2002) The construction industry as a loosely coupled system: Implications for productivity and innovation. Construction Management \& Economics, 20(7), 621-31.

Egan, J (1998) Rethinking construction, London: Department of Trade and Industry.

Eriksson, P E (2010) Partnering: What is it, when should it be used, and how should it be implemented? Construction Management and Economics, 28(9), 905-17.

Eriksson, P E and Westerberg, M (2011) Effects of cooperative procurement procedures on construction project performance: A conceptual framework. International Journal of Project Management, 29(2), 197-208.

Eurostat (2000) Production and productivity in the european union, Luxembourg: Office for Official Publications of the European Communities.

Fabbe-Costes, N, Jahre, M and Roussat, C (2009) Supply chain integration: The role of logistics service providers. International Journal of Productivity and Performance Management, 58(1), 71-91.

Fearne, A and Fowler, N (2006) Efficiency versus effectiveness in construction supply chains: The dangers of "lean" thinking in isolation. Supply Chain Management, 11(4), 283-7.

Fellows, R and Liu, A M M (2012) Managing organizational interfaces in engineering construction projects: Addressing fragmentation and boundary issues across multiple interfaces. Construction Management and Economics, 30(8), 653-71.

Fernie, S and Tennant, S (2013) The non-adoption of supply chain management. Construction Management and Economics, 31(10), 1038-58.

Flyvbjerg, B (2006) Five misunderstandings about case-study research. Qualitative Inquiry, 12(2), 219-45.

Forrester, J W (1958) Industrial dynamics: A major breakthrough for decision makers. Harvard Business Review, 36(4), 37-66.

Frödell, M (2014) Organisation of purchasing and buyer-supplier relationships in large construction companies, PhD Thesis, Department of Civil and Environmental Engineering, Chalmers University of Technology.

Fulford, R and Standing, C (2014) Construction industry productivity and the potential for collaborative practice. International Journal of Project Management, 32, 315-26.

Hamzeh, F R, Tommelein, I D, Ballard, G and Kaminsky, P M (2007) Logistics centers to support projectbased production in the construction industry. In: 15th Annual Conference of the International Group 
for Lean Construction, Pasquire, C L, C.L. and Tzortzopoulos, P, Eds.), East Lansing, Michigan, USA, 181-91.

Harland, C M (1996) Supply chain management: Relationships, chains and networks. British Journal of Management, 7, 63-80.

Hertz, S and Alfredsson, M (2003) Strategic development of third party logistics providers. Industrial Marketing Management, 32(2), 139-49.

Hwang, B-G, Thomas, S R, Haas, C T and Caldas, C H (2009) Measuring the impact of rework on construction cost performance. Journal of Construction Engineering \& Management, 135(3), 187-98.

Jesson, J K, Matheson, L and Lacey, F M (2011) Doing your literature review. London: SAGE Publications Ltd.

Josephson, P-E and Saukkoriipi, L (2005) Slöseri i byggprojekt. Behov av förändrat synsätt., Göteborg: FoU-väst.

Josephson, P-E and Chao, M (2014) Use and non-use of time in construction of new multi-dwelling buildings in sweden. International Journal of Construction Management, 14(1), 37-46.

Kadefors, A (1995) Institutions in building projects: Implications for flexibility and change. Scandinavian Journal of Management, 11(4), 395-408.

Lai, K H, Cheng, T C E and Yeung, A C L (2004) An empirical taxonomy for logistics service providers. Maritime Economics and Logistics, 6(3), 199-219.

Lambert, D M and Cooper, M C (2000) Issues in supply chain management. Industrial Marketing Management, 29, 65-83.

Langley, C J (2015) 2016 third-party logistics study: The state of logistics outsourcing, the annual study on the state of logistics outsourcing, USA: C. John Langley, Jr. (ed.) and Capgemini.

Larson, P D and Halldorsson, A (2004) Logistics versus supply chain management: An international survey. International Journal of Logistics Research and Applications, 7(1), 17-31.

Larsson, B, Hjort, B, Söderlind, L and Wennersten, M (2008) Logistik vid husbyggnad: Några praktikfall, Göteborg: FoU-Väst.

Lindén, S and Josephson, P E (2013) In-housing or out-sourcing on-site materials handling in housing? Journal of Engineering, Design and Technology, 11(1), 90-106.

Liu, C-L and Lyons, A C (2011) An analysis of third-party logistics performance and service provision. Transportation Research Part E: Logistics and Transportation Review, 47(4), 547-70.

Love, P E D, Skitmore, M and Earl, G (1998) Selecting a suitable procurement method for a building project. Construction Management \& Economics, 16(2), 221-33.

Marasco, A (2008) Third-party logistics: A literature review. International Journal of Production Economics, 113(1), 127-47.

Meng, X (2012) The effect of relationship management on project performance in construction. International Journal of Project Management, 30(2), 188-98.

Meng, X (2013) Change in uk construction: Moving toward supply chain collaboration. Journal of Civil Engineering \& Management, 19(3), 422.

Mentzer, J T, DeWitt, W, Keebler, J S, Min, S, Nix, N W, Smith, C D and Zacharia, Z G (2001) Defining supply chain management. Journal of Business Logistics, 22(2), 1-25.

Meredith, J (1993) Theory building through conceptual methods. International Journal of Operations \& Production Management, 13(5), 3-11.

Meredith, J R (2001) Reconsidering the philosopical basis of or/ms. Operations Research, 49(3), 325-33.

Miller, C J M, Packham, G A and Thomas, B C (2002) Harmonization between main contractors and subcontractors: A prerequisite for lean construction? Journal of Construction Research, 3(1), 67-82.

Scholman, H S A (1997) Uitbesteding door hoofdaannemers (subcontracting by main contractors). The Netherlands: Econ. Instituut voor de Bouwnijverheid, Amsterdam.

Segerstedt, A and Olofsson, T (2010) Supply chains in the construction industry. Supply Chain Management: An International Journal, 15(5), 347-53.

Selviaridis, K and Spring, M (2007) Third party logistics: A literature review and research agenda. International Journal of Logistics Management, 18(1), 125-50.

Skjoett-Larsen, T (2000) Third party logistics-from an interorganizational point of view. International Journal of Physical Distribution \& Logistics Management, 30(2), 112-27.

Sobotka, A and Czarnigowska, A (2005) Analysis of supply system models for planning construction project logistics. Journal of Civil Engineering and Management, 11(1), 73-82.

Statistics Sweden (2015), Building price index with deduction for allowances and cpi [Online], Statistics Sweden (SCB), Available: http://bit.ly/1UsLCxb [Accessed: 22nd of February 2016]. 
Strandberg, J and Josephson, P-E (2005) What do construction workers do? Direct observations in housing projects. In: Proceedings of 11th Joint CIB International Symposium Combining Forces, Advancing Facilities management and Construction through Innovation, Helsiniki, 184-93.

Thunberg, M and Persson, F (2013) Using the scor model's performance measurements to improve construction logistics. Production Planning \& Control, 25(13-14), 1065-78.

van Laarhoven, P, Berglund, M and Peters, M (2000) Third-party logistics in europe--five years later. International Journal of Physical Distribution \& Logistics Management, 30(5), 425.

Voss, C (2009) Case research in operations management. In: Karlsson, C (Ed.), Researching operations mangement, pp. 162-95. New York: Routledge.

Vrijhoef, R and Koskela, L (2000) The four roles of supply chain management in construction. European Journal of Purchasing \& Supply Management, 6(3-4), 169-78.

Wacker, J G (1998) A definition of theory: Research guidelines for different theory-building research methods in operations management. Journal of Operations Management, 16(4), 361-85.

Winch, G M (2001) Governing the project process: A conceptual framework. Construction Management and Economics, 19(8), 799-808. 